\title{
INTERFERÊNCIA DE Euphorbia heterophylla NO CRESCIMENTO E ACÚMUlo de MACRONUTRIENTES DA SOJA ${ }^{1}$
}

\author{
Interference of Euphorbia heterophylla in the Growth and Macronutrient Accumulation of \\ Soybean
}

\author{
CARVALHO, L.B. ${ }^{2}$, BIANCO, S. ${ }^{3}$ e GUZZO, C.D. ${ }^{4}$
}

\begin{abstract}
RESUMO - O grau de interferência depende da densidade de plantas daninhas que infestam a soja. O objetivo deste trabalho foi avaliar características de crescimento e nutrição mineral da soja mantida em convivência com densidades crescentes de Euphorbia heterophylla. O experimento foi conduzido em Jaboticabal, SP, Brasil, entre outubro e dezembro de 2008, em vasos mantidos em campo aberto. Os tratamentos consistiram em submeter uma planta de soja por vaso à convivência com $0,1,2,4,8$ e 16 plantas de $E$. heterophylla por vaso, da semeadura até o início do florescimento. Nesse periodo, avaliaram-se, apenas na soja, a altura e o número de trifólios, e em ambas as espécies, a matéria seca e o acúmulo de macronutrientes. Observou-se variação na altura de plantas e redução no número de trifólios e no acúmulo de matéria seca e macronutrientes da soja devido ao maior acúmulo de matéria seca e macronutrientes por densidades crescentes de E. heterophylla. Conclui-se que a soja mantida em convivência com E. heterophylla teve o crescimento e o acúmulo de macronutrientes reduzidos em razão da interferência imposta pela planta daninha.
\end{abstract}

Palavras-chave: amendoim-bravo, competição por nutrientes, Glycine max.

\begin{abstract}
The degree of weed interference depends on the density of the weeds infesting the soybean crop. The objective of this work was to evaluate the growth and mineral nutrition characteristics in soybean maintained in coexistence with increasing densities of Euphorbia heterophylla. The experiment was carried out in Jaboticabal, SP, Brazil, from October through December 2008, in pots maintained under open field conditions. The treatments consisted in submitting one soybean plant per pot to coexistence with $0,1,2,4,8$ and 16 plants of E. heterophylla per pot, from sowing until the beginning of soybean flowering. At this period, only height and number of leaves were evaluated in soybean, while dry matter and macronutrient accumulation were evaluated in both species. Variation in plant height and reduction in the number of leaves and dry matter and macronutrient accumulation of soybean were observed due to the higher accumulation of dry matter and macronutrients per increasing densities of $\boldsymbol{E}$. heterophylla. It was concluded that growth and macronutrient accumulation of soybean maintained in coexistence with $\boldsymbol{E}$. heterophylla were reduced due to weed interference.
\end{abstract}

Keywords: wild poinsettia, competition for nutrients, Glycine max.

\section{INTRODUÇÃO}

A soja (Glycine max) é destaque entre as principais oleaginosas produzidas no mundo
(Silva et al., 2009). Nos últimos anos, principalmente com a abertura de novas áreas sob vegetação de cerrado, o Brasil tornou-se o segundo maior produtor do mundo, com produção

Recebido para publicação em 19.5.2009 e na forma revisada em 12.3.2010.

2 Doutorando em Agronomia (Produção Vegetal), FCAV/UNESP, Via de acesso Prof. Paulo Donato Castellane, s/n, Depto. Biologia Aplicada à Agropecuária, 14884-900, Jaboticabal-SP, Bolsista CNPq, <agrolbcarvalho@gmail.com>; ${ }^{3}$ Prof. Adjunto Dep. de Biologia Aplicada à Agropecuária, FCAV/UNESP, <sbianco@fcav.unesp.br>; ${ }^{4}$ Mestrando em Agronomia (Produção Vegetal), FCAV/UNESP. Bolsista CNPq, <emaildoguzzo@msn.com>. 
superior a 58 milhões de toneladas de grãos, em área estimada de 21,24 milhões de hectares (Conab, 2009).

A presença de plantas daninhas em lavouras de soja pode alterar seu desenvolvimento, por promover competição pelos recursos do meio, como água, luz e nutrientes, reduzindo a disponibilidade desses recursos para a cultura e causando redução na produtividade de grãos devido aos efeitos da interferência sobre as variáveis que definem a produtividade da cultura (Silva et al., 2008). Os efeitos decorrentes da interferência de plantas daninhas sobre características de plantas cultivadas podem comprometer o desenvolvimento de estruturas reprodutivas e afetar os componentes da produtividade de grãos (Lamego et al., 2004).

Entre as plantas daninhas importantes na cultura da soja, vem-se destacando Euphorbia heterophylla (amendoim-bravo, leiteiro), principalmente em lavouras transgênicas, onde essa espécie tem sido selecionada devido à sua tolerância ao glyphosate (Vidal et al., 2007; Powles, 2008). A interferência dessa planta daninha pode influenciar negativamente o desenvolvimento das plantas de soja. Adelusi et al. (2006) observaram que o número de foliolos foi reduzido pela interferência imposta por E. heterophylla, enquanto, além deles, Willard et al. (1994) e Rizzardi et al. (2004) verificaram que a presença de plantas de E. heterophylla convivendo com a soja reduziu seu acúmulo de matéria seca. Além disso, Bianco et al. (2007) destacaram que essa planta daninha é um forte competidor por nutrientes com a soja, sobretudo no estádio de florescimento, período em que a soja tem maior requerimento nutricional.

O grau da interferência, porém, é influenciado diretamente pela densidade populacional da planta daninha que convive com a cultura da soja (Lamego et al., 2005). Assim, tem-se como hipótese que haverá maior prejuízo para a soja à medida que se aumentar a densidade de $E$. heterophylla. Portanto, o objetivo deste trabalho foi avaliar características de crescimento e nutrição mineral da soja mantida em convivência com densidades crescentes de E. heterophylla.

\section{MATERIAL E MÉTODOS}

O experimento foi conduzido em vasos de plástico com capacidade para 7 litros e dimensões de $26 \mathrm{~cm}$ de diâmetro e $22 \mathrm{~cm}$ de altura, entre os meses de outubro e dezembro de 2008, em Jaboticabal, SP, Brasil. Os vasos foram mantidos em campo aberto, sem controle das condições ambientais.

O substrato para o crescimento das plantas foi constituído da mistura de uma parte de esterco bovino com três partes de terra proveniente de Latossolo Vermelho eutrófico de textura argilosa, com as características químicas de $\mathrm{pH}\left(\mathrm{CaCl}_{2}\right)$ de 5,$6 ; 25 \mathrm{~g} \mathrm{dm}^{-3}$ de matéria orgânica; $87 \mathrm{mg} \mathrm{dm}^{-3}$ de $\mathrm{P}$ (resina); e 4, 43, 16 e $25 \mathrm{mmol}_{\mathrm{c}} \cdot \mathrm{dm}^{-3} \mathrm{de} \mathrm{K}{ }^{+}, \mathrm{Ca}^{2+}, \mathrm{Mg}^{2+}$ e $\mathrm{H}^{+} \mathrm{Al}^{3+}$, respectivamente; nenhuma aplicação de calcário ou fertilizante foi feita durante o desenvolvimento do experimento.

A semeadura foi realizada no dia 17 de outubro de 2008, na profundidade de $2 \mathrm{~cm}$. A soja cultivar Monsoy 7908 RR foi semeada no centro do vaso, e E. heterophylla, aleatoriamente, cobrindo toda a área do vaso. Foram estabelecidos seis tratamentos, e em todos foi mantida uma planta de soja por vaso, variando a densidade de $E$. heterophylla em 0 (testemunha), 1, 2, 4, 8 e 16 plantas por vaso. O experimento foi conduzido em delineamento de blocos casualizados, com oito repetições.

Os vasos foram regados periodicamente três vezes ao dia: no início da manhã, ao meiodia e no meio da tarde. Nenhum tratamento fitossanitário foi realizado no decorrer do experimento.

Quando a soja atingiu o estádio R1 na escala fenológica de Fehr \& Caviness (1977), ou seja, início de florescimento, as partes aéreas dela e de $E$. heterophylla foram cortadas rente ao solo e coletadas. Mensurou-se a distância da base da planta de soja até a inserção do último ramo emitido, denominando-se de altura, e contou-se o número de trifólios da soja. Em seguida, as plantas de soja e de $E$. heterophylla foram lavadas segundo Sarruge \& Haag (1974), para posterior determinação do teor de macronutrientes. Após a lavagem, as plantas foram secas à sombra e, posteriormente, em estufa a $70{ }^{\circ} \mathrm{C}$ por 96 horas. 
O material seco em estufa foi pesado em balança eletrônica de precisão de duas casas decimais, para determinação do acúmulo de matéria seca. Em seguida, esse material foi moído e encaminhado para a determinação dos teores de nitrogênio total $(\mathrm{N})$ e fósforo $(\mathrm{P})$, segundo Sarruge \& Haag (1974), potássio (K), cálcio (Ca) e magnésio (Mg), conforme Jorgensen (1977), e enxofre (S), segundo Vitti (1989). O acúmulo de macronutrientes foi calculado multiplicando-se o acúmulo de matéria seca da planta pelo teor do nutriente.

Os dados de altura, número de trifólios, matéria seca acumulada e macronutrientes acumulados da soja, além daqueles de matéria seca acumulada e macronutrientes acumulados de E. heterophylla, foram submetidos à análise de regressão.

\section{RESULTADOS E DISCUSSÃO}

O crescimento em altura da soja oscilou em função da densidade de plantas de E. heterophylla (Figura 1). De acordo com a equação ajustada, houve um pico de altura quando 1,34 planta de E. heterophylla foi mantida em convivência com uma planta de soja. Isso evidencia que ocorreu estiolamento da soja mantida em convivência com uma ou duas plantas de E. heterophylla, em relação

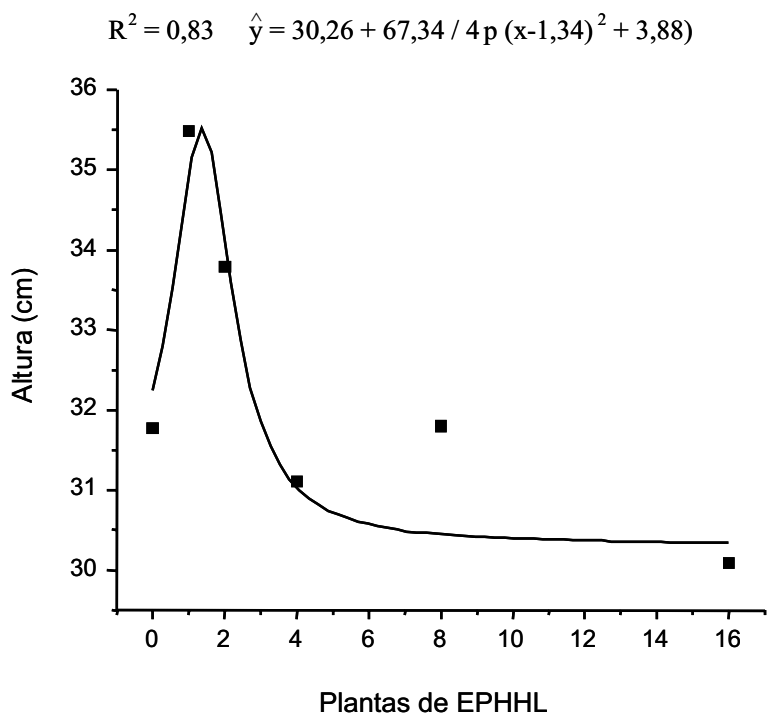

Figura 1 - Altura de plantas de soja, crescendo em convivência com Euphorbia heterophylla (EPHHL). Avaliação no início do estádio R1 (Fehr \& Caviness, 1977). àquela mantida livre da planta daninha. Além disso, pode-se inferir que a interferência das plantas daninhas afetou negativamente o crescimento em altura das plantas de soja à medida que a densidade de $E$. heterophylla foi aumentada em mais de duas plantas. Assim, em relação àquela mantida livre da convivência com $E$. heterophylla, a soja mantida com uma planta daninha cresceu $12 \%$ a mais em altura, enquanto aquela mantida com 16 plantas de E. heterophylla cresceu 5\% a menos em altura.

Alterações na qualidade e intensidade da luz incidente afetam o desenvolvimento das plantas cultivadas (Ballare \& Casal, 2000), pois as plantas daninhas refletem luz em determinado comprimento de onda que estimula o crescimento da cultura em altura, como forma de captar o máximo da radiação disponivel e sombrear as plantas daninhas (Radosevich et al., 1997). Ressalta-se que, morfologicamente, plantas de uma cultura serão mais altas quanto maior for a competição com as plantas daninhas, desde que a competição interespecífica não reduza os recursos do meio a ponto de limitar o crescimento da cultura.

O desenvolvimento do número de trifólios da soja foi reduzido em função da densidade de plantas de E. heterophylla (Figura 2). De acordo com a equação ajustada, a partir de

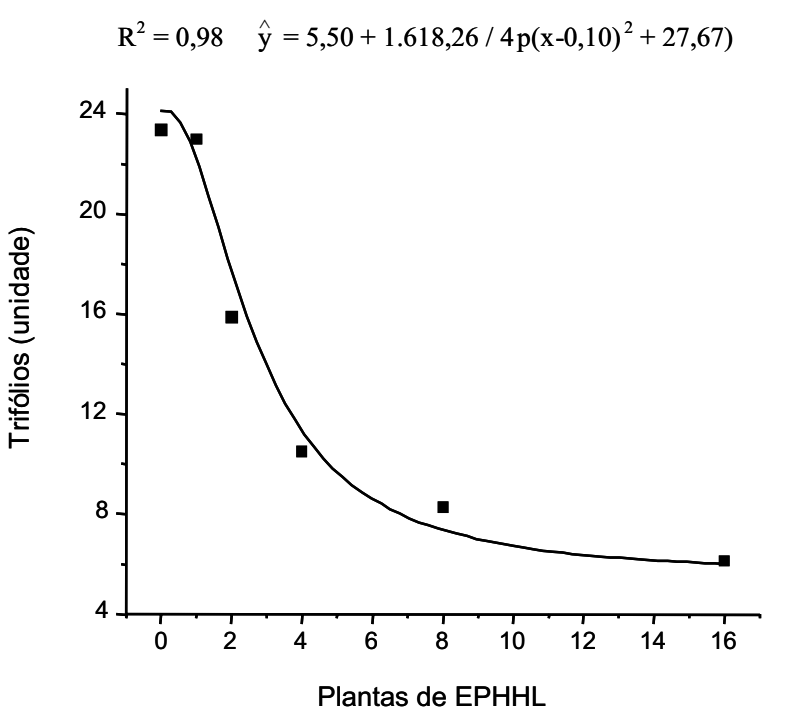

Figura 2 - Número de trifólios de soja, crescendo em convivência com Euphorbia heterophylla (EPHHL). Avaliação no início do estádio R1 (Fehr \& Caviness, 1977).

Planta Daninha, Viçosa-MG, v. 28, n. 1, p. 33-39, 2010 
0,10 planta de E. heterophylla mantida em convivência com a soja, houve diminuição no número de trifólios da cultura. Isso evidencia que ocorreu redução no número de trifólios à medida que foi estabelecida a convivência com a planta daninha. A redução no número de trifólios da soja mantida livre da convivência $\operatorname{com} E$. heterophylla em relação àquela mantida com 16 plantas daninhas foi de $74 \%$.

A redução no número de folíolos das plantas de soja que cresceram em convivência com E. heterophylla, verificada por Adelusi et al. (2006), corrobora o menor número de trifólios observado neste experimento. Segundo esses pesquisadores, essa redução deve-se à menor absorção de água e nutrientes pelas plantas de soja devido à interferência imposta pela planta daninha.

O acúmulo de matéria seca da soja foi reduzido à medida que a convivência com $E$. heterophylla foi estabelecida (Figura 3). Além disso, observou-se rápido acúmulo de matéria seca de $E$. heterophylla nas densidades mais baixas, porém, à medida que se foi aumentando a densidade da planta daninha, houve tendência de estabilização do acúmulo de matéria seca da espécie, principalmente devido à interferência intraespecífica. Comparando a matéria seca acumulada pelas duas espécies, constata-se que, à medida que
E. heterophylla acumula mais matéria seca, ocorre redução no acúmulo por parte da soja. Portanto, a redução no acúmulo de matéria seca da soja mantida livre da convivência com a planta daninha, comparada com aquela mantida com 16 plantas de E. heterophylla, foi de $82 \%$; já o acréscimo no acúmulo de matéria seca da planta daninha foi de $156 \%$, comparando a densidade de 1 e 16 plantas de E. heterophylla.

Reduções no acúmulo de matéria seca das plantas de soja mantidas em convivência com $E$. heterophylla foram verificadas por Willard et al. (1994), Rizzardi et al. (2004) e Adelusi et al. (2006), corroborando os resultados observados. Essa redução deve-se à competição interespecífica da soja com E. heterophylla, principalmente por água e nutrientes (Adelusi et al., 2006), destacando-se que a porcentagem de redução varia de acordo com a quantidade de recursos do ambiente disponiveis às plantas que estão crescendo em convivência (Willard et al., 1994; Rizzardi et al., 2004). Outro fator que explica essa redução é a maior capacidade competitiva da planta daninha em relação à cultura da soja (Rizzardi et al., 2004).

Os teores de macronutrientes em soja no estádio R1 e E. heterophylla oscilaram no período avaliado, não evidenciando qualquer relação com o aumento na densidade da planta

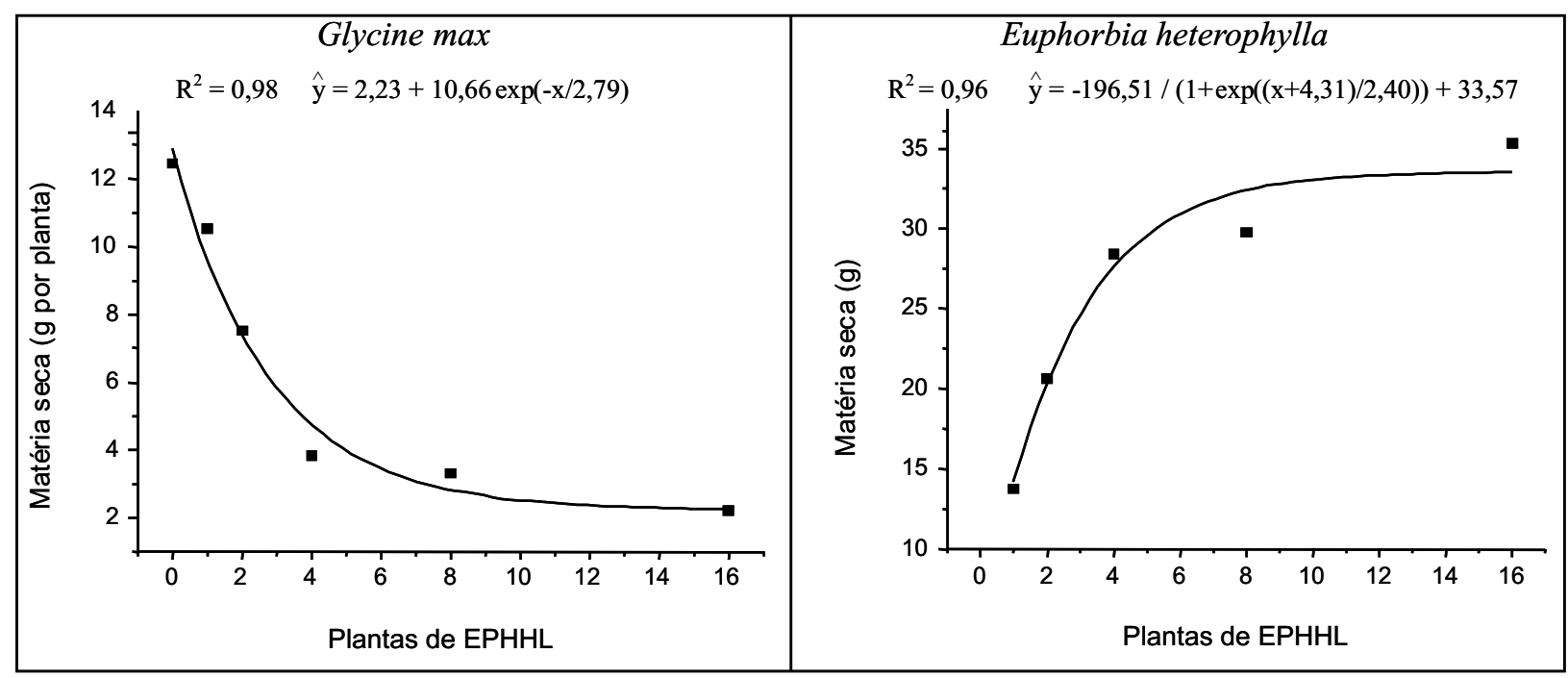

Figura 3 - Acúmulo de matéria seca de Glycine max e de densidades crescentes de Euphorbia heterophylla (EPHHL), crescendo em convivência. Avaliação no início do estádio R1 (Fehr \& Caviness, 1977). 
daninha. Em soja, o teor de $\mathrm{N}$ variou de 29,00 a $34,13 \mathrm{~g} \mathrm{~kg}^{-1}$; o de $\mathrm{P}$, de 1,99 a 2,43 $\mathrm{g} \mathrm{kg}^{1}$; o de $\mathrm{K}$, de 20,60 a $23,15 \mathrm{~g} \mathrm{~kg}^{-1}$; o de $\mathrm{Ca}$, de 8,00 a $8,68 \mathrm{~g} \mathrm{~kg}^{-1}$; o de $\mathrm{Mg}$, de 3,15 a $3,48 \mathrm{~g} \mathrm{~kg}^{-1}$; e o de $\mathrm{S}$, de 0,69 a $1,05 \mathrm{~g} \mathrm{~kg}^{-1}$. Em E. heterophylla, o teor de $\mathrm{N}$ variou de 10,63 a 13,73 $\mathrm{g} \mathrm{kg}^{1}$; o de $\mathrm{P}$, de 2,23 a 2,80 $\mathrm{g} \mathrm{kg}^{-1}$; o de $\mathrm{K}$, de 23,78 a $26,68 \mathrm{~g} \mathrm{~kg}^{-1}$; o de Ca, de 6,65 a 7,90 $\mathrm{g} \mathrm{kg}^{-1}$; o de $\mathrm{Mg}$, de 1,85 a $2,23 \mathrm{~g} \mathrm{~kg}^{-1}$; e o de $\mathrm{S}$, de 0,48 a $0,87 \mathrm{~g} \mathrm{~kg}^{-1}$.

O acúmulo de todos os macronutrientes da soja foi reduzido à medida que a convivência com $E$. heterophylla foi estabelecida (Figura 4), pelo fato de a planta daninha ter aumentado seu acúmulo de macronutrientes à medida que se aumentou sua densidade, principalmente até oito plantas (Figura 5). A partir dessa densidade, houve tendência de estabilização no acúmulo de macronutrientes de E. heterophylla, principalmente de $\mathrm{P}, \mathrm{Ca}$, $\mathrm{Mg}$ e S. A redução no acúmulo de $\mathrm{N}$ em soja foi de $85 \%$; de P, $85 \%$; de $\mathrm{K}, 84 \%$; de Ca, $83 \%$; de $\mathrm{Mg}, 81 \%$; e de $\mathrm{S}, 89 \%$, comparando-se a soja livre da convivência com aquela mantida em convivência com 16 plantas de $E$. heterophylla por vaso.

E. heterophylla mostrou ser uma planta daninha com alta capacidade de competição por macronutrientes em relação à soja, devido às grandes reduções nos acúmulos desses nutrientes observadas neste experimento. Estudando a marcha de absorção dessas duas espécies em condições controladas, Bianco et al. (2007) verificaram que, na fase de florescimento da soja, o requerimento nutricional de ambas as espécies aumenta, atingindo a maior taxa de acúmulo diário de macronutrientes, evidenciando que E. heterophylla pode trazer muitos prejuízos à soja em termos de competição por macronutrientes. No período de florescimento ocorre uma força mobilizadora de nutrientes e assimilados, em razão

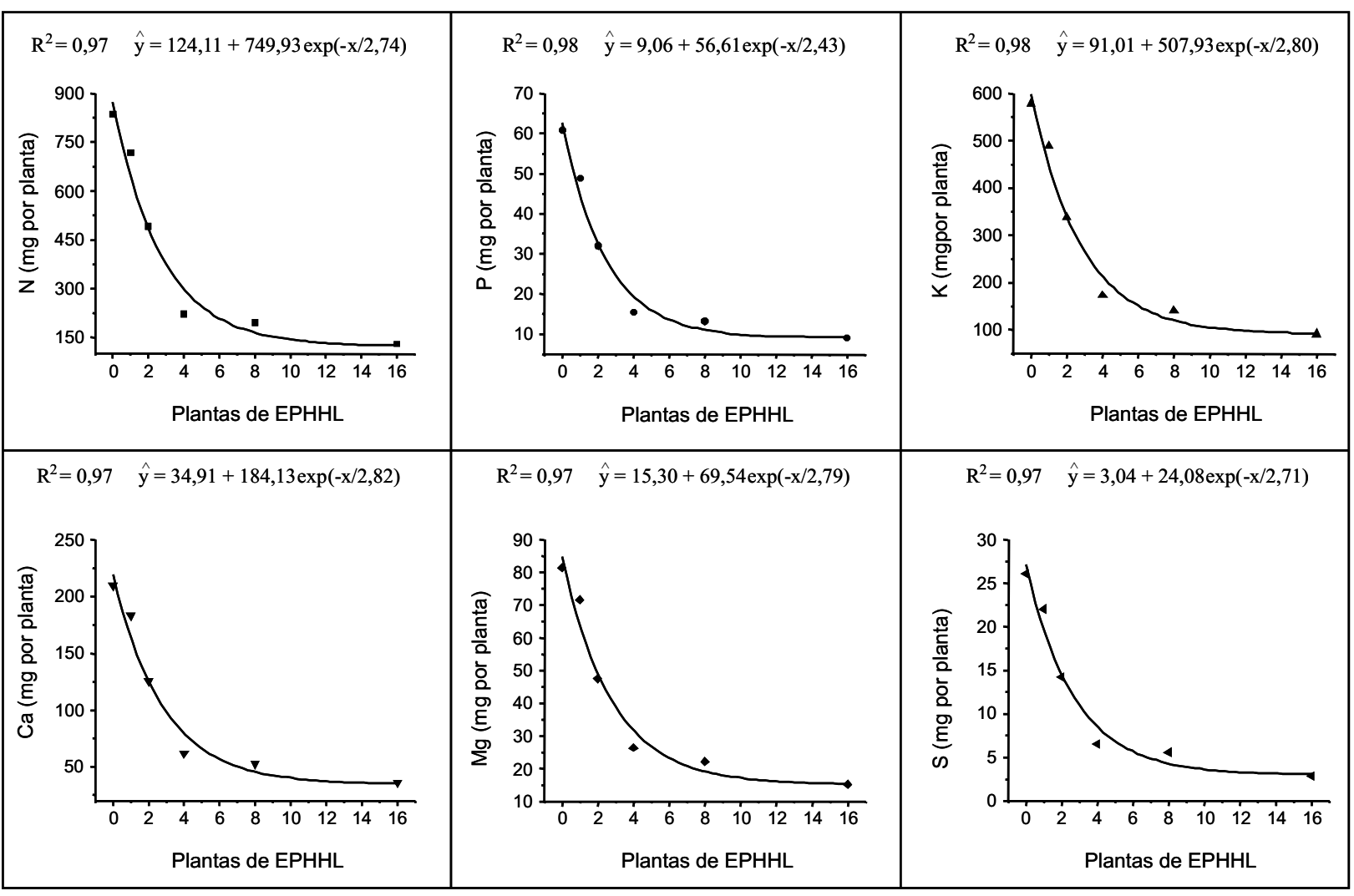

Figura 4 - Acúmulo de macronutrientes por Glycine max, crescendo em convivência com Euphorbia heterophylla (EPHHL). Avaliação no início do estádio R1 (Fehr \& Caviness, 1977). 


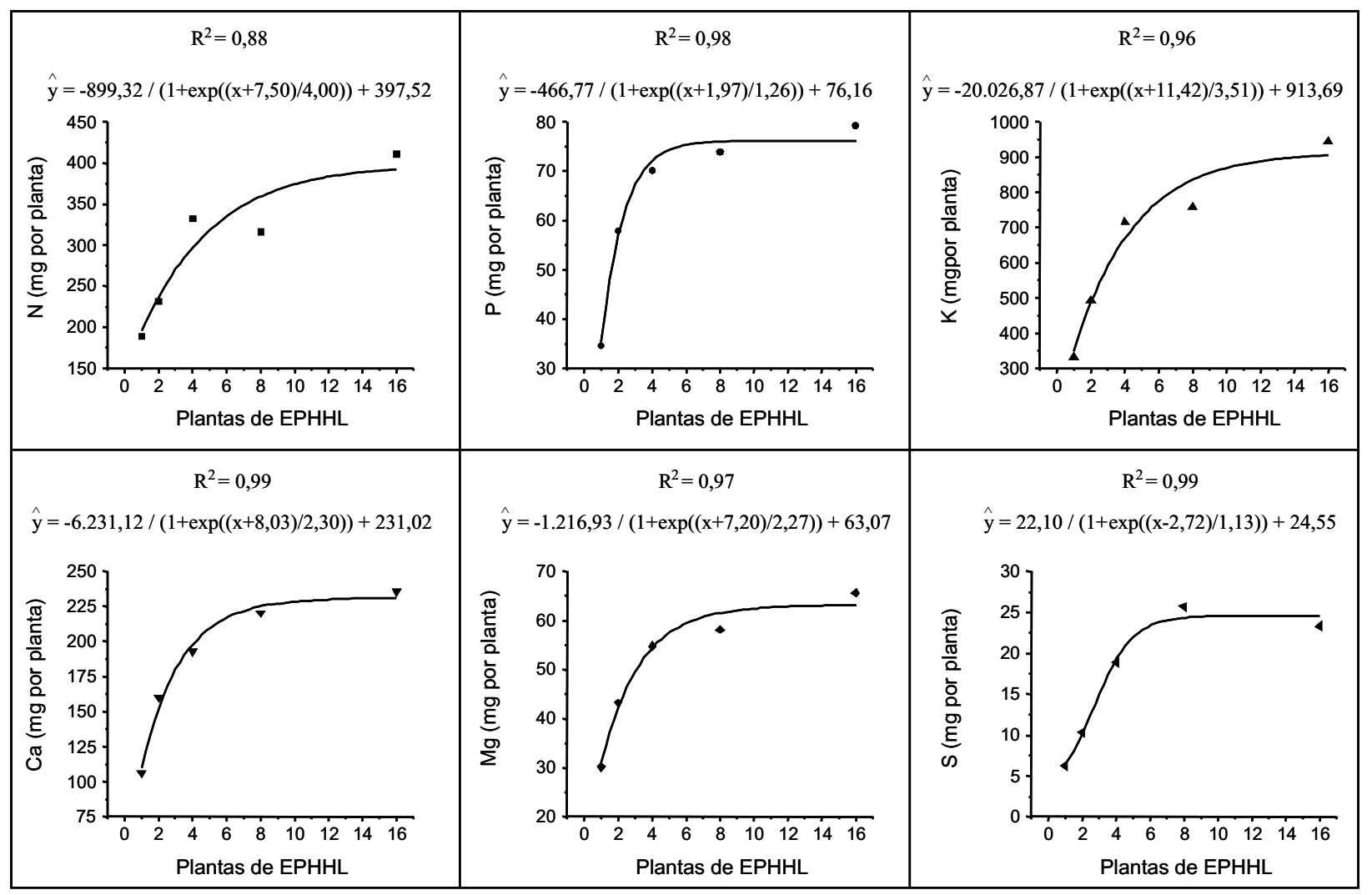

Figura 5 -Acúmulo de macronutrientes por plantas de Euphorbia heterophylla (EPHHL), crescendo em convivência com Glycine max. Avaliação no início do estádio R1 (Fehr \& Caviness, 1977).

do aumento da atividade metabólica, associada à atividade hormonal e à divisão e crescimento celular, o que acarreta maior requerimento nutricional pelas plantas (Taiz \& Zeiger, 2002).

Apesar de a soja mantida em convivência com uma ou duas plantas de $E$. heterophylla ter apresentado maior crescimento em altura (Figura 1), em relação às demais densidades e à soja livre da planta daninha, o número de trifólios (Figura 2) e o acúmulo de matéria seca (Figura 3) e macronutrientes (Figura 4) foram reduzidos, como discutido anteriormente. Portanto, o ganho em altura não propiciou maior desenvolvimento da soja, havendo, em vez disso, detrimento da cultura em função do estresse causado pela interferência de E. heterophylla. $\mathrm{O}$ estresse causado pelas plantas daninhas acarreta alterações morfofisiológicas nas plantas de soja, com posterior reflexo na sua produção (Lamengo et al., 2005). Assim, pode inferir-se que as alterações observadas na soja irão acarretar menor desenvolvimento das plantas e, consequentemente, redução da produtividade final da cultura, caso seja mantida em convivência com $E$. heterophylla.

Conclui-se que a soja mantida em convivência com $E$. heterophylla tem o crescimento e o acúmulo de macronutrientes reduzidos em razão da interferência imposta pela planta daninha.

\section{LITERATURA CITADA}

ADELUSI, A. A. et al. Interference of Euphorbia heterophylla Linn. on the growth and reproductive yield of soybean (Glycine $\max$ Linn.) Merrill. Res. J. Bot., v. 1, n. 2, p. 85-94, 2006.

BALLARE, C. L.; CASAL, J. J. Light signals perceived by crop and weed plants. Field Crops Res., v. 67, n. 2, p. 149-160, 2000.

BIANCO, S.; PITELLI, R. A.; CARVALHO, L. B. Estudo comparativo do acúmulo de massa seca e macronutrientes por plantas de Glycine max (L.) Merr. e Euphorbia heterophylla

L. Ensaios Ci., v. 11, n. 2, p. 61-72, 2007. 
COMPANHIA NACIONAL DE ABASTECIMENTO CONAB, 2009. Safra. Disponível em: $<\mathrm{http} / / /$ www.conab.gov.br/conabweb/download/safra/ 3graos_08.09.pdf>. Acesso em: 15 jan. 2009.

FEHR, W. R.; CAVINESS, C. E. Stages of soybean development. Ames: Iowa State University, 1977. 12 p. (Special Report, 80)

JORGENSEN, S. S. Metodologia utilizada para análises químicas de rotina: guia analítico. Piracicaba: CENA, 1977. $24 \mathrm{p}$.

LAMEGO, F. P. et al. Tolerância a interferência de plantas competidoras e habilidade de supressão por genótipos de soja - II. Resposta de variáveis de produtividade. Planta

Daninha, v. 22, n. 4, p. 491-498, 2004.

LAMEGO, F. P. et al. Tolerância a interferência de plantas competidoras e habilidade de supressão por cultivares de soja - I. Resposta de variáveis de crescimento. Planta Daninha, v. 23, n. 3 , p. $405-414,2005$.

POWLES, S. B. Evolved glyphosate-resistant weeds around the world: lessons to be learnt. Pest Manag. Sci., v. 64, n. 4, p. $360-365,2008$.

RADOSEVICH, S. R.; HOLT, J.; GHERSA, C. Weed ecology: implications for management. 2.ed. New York: John Wiley \& Sons, 1997. 589 p.
RIZZARDI, M. A. et al. Interferência de populações de Euphorbia heterophylla e Ipomoea ramosissima isoladas ou em misturas sobre a cultura de soja. Planta Daninha, v. 22, n. 1, p. 29-34, 2004.

SARRUGE, J. R.; HAAG, H. P. Análises químicas em plantas. Piracicaba: Escola Superior de Agricultura Luiz de Queiroz, 1974. 56 p.

SILVA. A. F. et al. Densidades de plantas daninhas e épocas de controle sobre os componentes de produção da soja.

Planta Daninha, v. 26, n. 1, p. 65-71, 2008.

SILVA, A. F. et al. Período anterior à interferência na cultura da soja-RR em condições de baixa, média e alta infestação.

Planta Daninha, v. 27, n. 1, p. 57-66, 2009.

TAIZ, L.; ZEIGER, E. The control of flowering. In.: TAIZ, L.; ZEIGER, E. Plant physiology. 3.ed. Sunderland: Sinauer, 2002. p. 559-590.

VIDAL, R. A. et al. Glyphosate resistant biotypes of wild poinsettia (Euphorbia heterophylla (L.)) and its risk analysis on glyphosate-tolerant soybeans. J. Food Agric. Environ., v. 5, n. 2 , p. $265-269,2007$.

VITTI, G. C. Avaliação e interpretação do enxofre no solo e na planta. Jaboticabal: FUNEP, 1989. 37 p.

WILLARD, T. S. et al. Interference of wild poinsettia (Euphorbia heterophylla) with soybean (Glycine max). Weed Technol., v. 8, n. 4, p. 679-683, 1994. 